\title{
Mood management: an updated toolkit
}

\section{Josep Quer \\ ICREA-Universitat Pompeu Fabra}

The five articles in this Special Issue have contributed an important number of new insights and (re)analyses of empirical data sets concerning the distribution and interpretation of indicative and subjunctive moods mainly in Romance and Balkan languages. The languages analyzed here in most detail are Italian, Spanish and Greek.

The question whether a set of cases in mood distribution should be considered as the core case for our understanding of the problems is answered directly or indirectly in all the contributions with varying responses. Kempchinsky, for instance, relying on a well-known generalisation and deepening the analysis in previous work of hers, states that the core occurrences of subjunctive are the clausal complements to desiderative and directive predicates, which display lexically selected subjunctive. For her, these instances arise as a result of the selection in the syntax of an uninterpretable W(orld)feature in the embedded C-domain (more specifically, in Force), as well as of the presence of a quasi-imperative operator in the functional syntactic projection FinP. Other instances of non lexically selected subjunctive do not involve such an operator. Additionally, the W-feature in Force is interpretable in such cases. In this fashion Kempchisnky manages to account for the well-known properties of the two types of subjunctives, most prominently disjoint subject reference effects and temporal interpretation restrictions.

The other authors do not share this point of view and tend to address such core subjunctive cases next to other sets of non-selected subjunctives as well, like conditionals. In general, the contribution of subjunctive as a category is decomposed into a number of elements in the morphosyntax that compositionally lead to the surface makeup and to the interpretations ascribed to this mood. Let us have a look at the different approaches separately, as the assumptions and implementations differ significantly from case to case.

Giorgi's proposal stems from previous extensive work on the syntax and interpretation of the phenomenon of double access reading (DAR) for embedded finite verbal forms. The crucial property of DAR is that the embedded tense is not only interpreted with respect to the matrix eventuality but also with respect to the speaker's temporal coordinate, that is the speech time of the utterance context. The representation of this coordinate materializes in the syntactic projection of a $C$ endowed with a feature that serves as a pointer to the context of utterance. In general, subjunctive clauses do not project such a C: subjunctive morphology does not convey relational tenses, but rather constitutes a sort of temporal agreement with the main verb or alternatively it can be anchored to an explicit or implicit temporal expression. In this respect, Giorgi's analysis aligns with the idea of subjunctive as defective/anaphoric tense, but gives it a new place within the explanation of DAR phenomena. The properties of the matrix predicate are crucial. On the one hand, verbs of communication typically select for the indicative in Italian, as they represent the speaker's coordinate in the embedded C. On the other hand, verbs reporting an epistemic state do not represent it in their complement clauses and consequently display subjunctive morphology.

Giorgi discusses at length the hybrid behaviour of a verb like ipotizzare 'to hypothise' in Italian, which shows routine subjunctive selection at face value. However, she argues that under a communication verb interpretation of ipotizzare, no strict sequence of tense is at play and complementizer deletion is impossible precisely 
because the speaker's coordinate has been projected in the syntax, allowing DAR. Under an epistemic state interpretation of the same verb, complementizer deletion is possible and no DAR-effects arise. This constitutes an argument for Giorgi to establish that the predicates showing ambiguous DAR behaviour select for essentially different types of argument clauses and thus for different interpretations of the same surface subjunctive morphology.

Roussou's article concentrates on the contribution of the Greek particle na to the category traditionally known as subjunctive in this language, which is not morphologically marked in the verbal paradigm. In her current approach, the mood characteristic of $n a$ is only secondary. In this piece of work she attempts to derive the (non-)control properties of na-clauses, and to extend the core of the analysis to a language like English which does have non-finite complementation. Unlike in Romance, no obviation effects are at play with volitional predicates in Greek. The key to her analysis is that $n a$ is a nominal locative element that can take a CP as its complement, giving rise to subjunctive structures. As a consequence of its nominal properties, na blocks, on the one hand, lexicalization of a DP subject in the EPP position and, on the other, it forms a chain with agreement, jointly determining the interpretation of the subject. Control of na-clauses amounts to binding of $n a$ by one of the matrix arguments. Control predicates such as modals or aspectuals impose a single event reading of the clausal domains and such event composition results in argument structure composition. The temporal restrictions observed follow from this basic property. Non-control predicates like volitionals do not trigger this type of event unification. From this point of view, the syntax and semantics of Greek subjunctive clauses is determined by the binding possibilities of the particle na as a locative pronominal element. Roussou's proposal joins in this the line of analysis that takes the dependent character of subjunctive as derivative from its nominal properties, here explicitly argued to reside in the particle na itself.

Giannakidou's account of Greek subjunctive also concentrates on the nature and the semantic contribution of the particle $n a$ and the perfective nonpast (PNP) verbal forms that can only occur in the scope of $n a$ and similar particles (tha, $a s, a n$ ). The main tenet is that this verbal form is referentially deficient, in the sense that it cannot be interpreted as a free variable that could be identified at some point with the utterance time of the context. The binding of its dependent time variable is carried out by na and similar particles, which introduce the variable $n$ (for now) in the syntax. The PNP denotes a forward moving interval whose left boundary is a variable $t$ that cannot be interpreted deictically. The introduction of $n$ by the PNP-licensing particles fixes the referential deficiency of the verbal form by filling in $n$ for its $t$ variable. When embedded, the lambda-bound $n$ of na cannot refer to the utterance time but to the relative $n$ of the matrix attitude. From this the veridicality status of $n a$-clauses, which is not uniform, can be derived. In main clauses, na is always embedded under a non veridical function (directive illocutionary force, for instance, or a modal adverbial). With this account, the author argues to have found evidence of an instance of polarity dependency in the temporal domain. In this respect, the proposal incorporates and combines the virtues of the approaches that analyzed subjunctive clauses as dependent nominals and dependent tenses, and puts the burden of the interpretation of the naclause on the item binding the so-called subjunctive particle.

In these four approaches the emphasis is laid on the specific interpretive contribution of each of the components of the morphosyntactic makeup of what is known as "subjunctive" in specific languages such as Greek, Italian or Spanish. Siegel chooses instead to explore a general interpretive characterization of indicative and 
subjunctive as a whole in Romance vs. Balkan languages. Following previous proposals by Portner and Schlenker, but departing from the widespread assumption that indicative is the default mood, she argues for indicative as the marked category of the opposition, while subjunctive would be the default that appears when the semantic contribution of indicative would be inappropriate. In Romance, indicative signals the supposition of the speaker commitment to the truth of the embedded proposition. However, in Balkan languages (including Romanian), indicative is used to express certainty on the part of the matrix subject, i.e. the holder of the ascribed attitude, and consequently it does not carry the presuppositional content that it has in Romance. A case discussed at length is subjunctive selection by factive-emotive predicates in Romance: Siegel argues that subjunctive surfaces in their argument clauses despite the fact that the speaker is committed to the truth of the proposition they convey by means of the factive presupposition of the matrix predicate; using the indicative in the embedded clause would lead to redundant repetition of such presupposition, and this is circumvented by resorting to the default represented by the subjunctive. In Balkan languages, on the other hand, given the different contribution of indicative, no such incompatibility arises and indicative surfaces in the same contexts.

A potential difficulty with this type of approach derives from the strategy to attach a specific meaning to a category as a whole. This has proven to be unfeasible for the subjunctive, but it cannot be straightforwardly applied to the indicative either. As noted by Siegel in fn. 3 of her article, the presupposition carried by the subjunctive in the examples discussed is not always linked to the speaker and can be attributed to some other relevant illocutionary agent. This aspect is decisive, as it constitutes the basis of the purported contrast of the interpretation of the indicative in Romance vs. Balkan languages. Additionally, some extra empirical data should have to be addressed under this light, like for instance the fact that that causative and implicative predicates in a Balkan language like Greek exclusively selects for the subjunctive:

$$
\begin{aligned}
& \text { a. Katafere na ton voithisi. } \\
& \text { manage.PST.3SG SUB him help.PNP.3SG } \\
& \text { 'S/he managed to help him.' } \\
& \text { b. } \quad \text { *Katafere }\{\text { pu / oti }\} \text { ton voithise. } \\
& \text { manage.PST.3SG that him help.PST.PFT.3SG }
\end{aligned}
$$

If we follow the same reasoning Siegel proposes for Balkan factive-emotives in a simple-minded fashion, the inherent factive or implicative reading of the argument clauses should not prevent the indicative from appearing, as in these languages there is no presupposition of the speaker attached to this mood, but this is contrary to fact. In any case, this empirical argument should be explored more throroughly across the Balkan languages referred to in Siegel's proposal.

A more general question arises in this connection, though: what does speaker commitment amount to in the opposition between asserted and presupposed meaning? This is certainly a non-trivial question for all analyses of mood that resort to these concepts. Other things being equal, we could expect that a main assertion and its rendition embedded under a first person assertive predicate should display opposite mood choice under the assumption that an indicative under a strong assertive like estar segur 'to be sure' in the first person arguably leads to redundant repetition of the 
supposition of speaker commitment, and we would expect subjunctive to surface in order to avoid the conflict, contrary to fact, as exemplified in (2):

\author{
a. És veritat. \\ be.PRS.IND.3SG truth \\ 'It's true.' \\ b. Estic segur que és veritat. \\ be.PRS.IND.1SG sure that be.PRS.IND.3SG truth \\ 'I'm sure that it's true.' \\ c. $\quad *$ Estic segur que sigui veritat. \\ be.PRS.IND.1SG sure that be.PRS.SUB.3SG truth
}

One could argue that only the lexical factivity of factive-emotive predicates involves presupposition and thus gives rise to repeated presuppositions if indicative is chosen in the complement clause, but then all the other cases that are argued to follow from "supposition of speaker commitment" fall out (see for instance Siegel's discussion of her example (34), where a first person belief predicate in Italian can only take subjunctive). It might be the case that this notion and its interaction with assertion/presupossition and old-/new-information need some fine-tuning for them to be able to account for the intricate distribution and interpretation of the moods and the subtle differences identified in the two groups of languages studied.

An interesting conclusion that appears prominently in virtually all of the contributions is that mood choice and interpretation is not rigidly determined by the lexical properties of the matrix predicate, but rather by the its interaction with other syntactic, semantic and pragmatic factors. Take for instance the cases of "mood attraction" discussed by Giorgi in her section 4.2.4. Another especially interesting case in this connection is the one mentioned in the introduction to this issue (see ex. (8) there): double mood selection with verbs of communication, depending on whether they report an assertion (indicative) or a command (subjunctive).
a. $\quad$ Il professore gli disse che parlava troppo. the teacher him say.PST.3SG that speak.PST.IND.3SG too-much 'The teacher told him that he was talking too much.'
b. Il professore gli disse che parlasse ad alta voce. the teacher him say.PST.3SG that speak.PST.SUB.3SG in high voice 'The teacher told him to speak loudly.' (from Wandruszka 1991)

A double-entry analysis for each verb that displays this hybrid behaviour clearly misses an insight into the workings of mood. Kempchisnky takes it into her account, for instance, and groups the subjunctive taking verbs of saying with lexical directives like 'to order', which feature the same quasi-imperative operator in their complements as volitives. Giorgi argues that, irrespective of the mood choice, verbs of saying and communication as a group project the speaker's coordinate, thus disallowing complementizer deletion. It is not clear, though, how the jussive or directive meaning arises when subjunctive is selected. An additional puzzle in the Italian data is represented by (4), from Giorgi and Pianesi (2004:205): 
Dicono (che) sia una stupida.

say.PRS.3PL that be.SUB.3SG a stupid.FEM

'They say that she is stupid.'

The crucial observation is that in this case the verb is not interpreted as a verb of communication, but as an epistemic one that ascribes an attitude, and consequently no speaker's coordinate is projected in the syntax, thus allowing for complemetizer deletion. This is a clear example where the interpretive output is determined by a conjunction of factors, and not simply by the matrix predicate or by the meaning attached to one mood or the other. The fact is that mood alternations in such examples exist and it remains to be determined whether there is a contrast in interpretation and, if that were the case, which one exactly (example from Wandruszka 1991: 439):

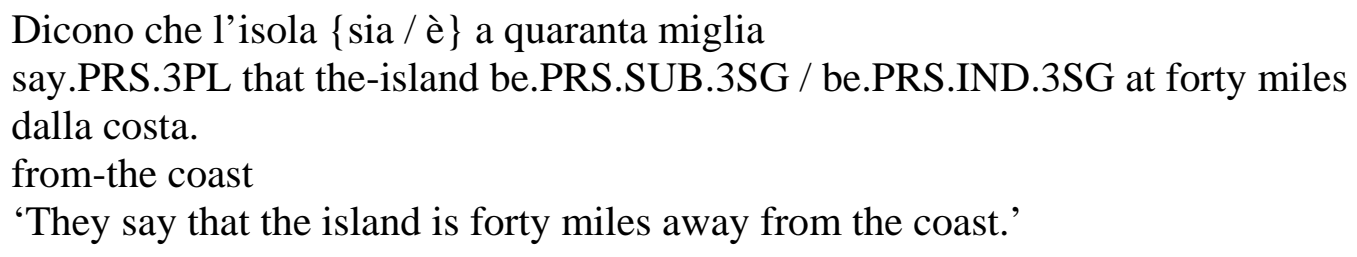

For an account like Siegel's that treats subjunctive as a default, it might seem difficult at face value to tease apart the two distinct instances of subjunctive under the same verb of communication. However, she offers a sketch of an analysis in terms of subjunctive as underspecified morphology for the embedded contexts where the imperative morphology is not available.

Mood selection under factive-emotives is addressed to different degrees in all contributions. All of them incorporate the particular semantic feature encoded by these predicates: factivity of their argument clauses. Siegel's approach in terms of avoidance of repetition of speaker's commitment presupposition has been briefly presented above. Giorgi postulates a specific factive $[+F]$ feature in the head Mood, where the (subjunctive) complementizer che resides, so here the lack of complementizer deletion with factives in Italian is not a consequence of the projection of the speaker's coordinate, but rather a result of the presence of a factive feature. Kempchinsky appeals to the dual nature of the semantics of factive emotives, i.e. both as factives and as predicates reporting the cognitive state or perspective point of the subject, and posits the existence of an operator as in volitionals, directives and implicatives. Although mentioned in some cases, the variation referred to in point $\mathrm{V}$ of the introduction does not receive specific treatment and is treated as a peripheral language-specific phenomenon.

Conditional clauses appear in some of the accounts. Giannakidou, for instance, discusses the role of the conditional complementizer an in Greek in the counterfactual readings arising with past imperfective forms in the protasis. Her account amounts to assigning the same semantic contribution to this particle as the other subjunctiveintroducing particles in the language: the introduction of the variable $n(o w)$, which then combines in a particular way with the interval introduced by the imperfective. Giorgi briefly deals with mood in conditional clauses-putting the imperfect indicative aside. She establishes that indicative conditionals are located with respect to the speaker's coordinate, but the protasis is not temporally anchored to the main clause. Conditional mood appears in the apodoses of subjunctive conditionals and Giorgi proposes that in such instances it is precisely the modality of the conditional form which inhibits the 
projection of the speaker coordinate and "licenses" past subjunctive in the protasis. It is also interesting to note that for her conditional verb forms actually convey a present, but since they are not indicative they do not give rise to DAR effects.

The divide in mood distribution between Romance and Balkan languages is addressed to a certain extent in all papers. We have already referred to Siegel's different characterization of the meaning of indicative in the two groups. Giorgi appeals to the lack of infinitives in the second group to suggest a possible locus of explanation for the difference, which for her amounts to the non-existence of DAR effects in Greek or Romanian. She further speculates about the possibility that in non-DAR languages the speaker's coordinate is projected, but used for other interpretive purposes than temporal interpretation. Roussou, Giannakidou and Kempchinsky also emphasize the lack of a subjunctive verbal paradigm in Balkan languages and put the burden of the divide with respect to Romance in the morphosyntactic makeup and the semantic mapping of the structures known as subjunctive in this group of languages. Kempchinsky, for instance, attributes the divide to the existence of a specific subjunctive complementizer in Balkan and its lack in Romance, which has to resort to a covert operator in Fin to mark the subjunctive clause as a true dependent. Roussou recalls the contrast in subject disjoint referent effects in Balkan and Romance and attributes the existence of such effects in the latter to the fact that these languages have morphological subjunctive realized in the I-system, whereas the complementizer que is insensitive to mood selection and does not mediate for the purposes of control, which is realized with infinitives.

From this brief review of the five articles as a whole, it should have become clear that, despite the differences in departure point, assumptions, implementation and empirical range covered, significant new insights are offered that broaden our understanding of the many phenomena and puzzles around the interpretation and distribution of indicative and subjunctive. At the same time, new avenues for inquiry have been put forth and will certainly lead to progress in the study of this domain and its theoretical implications.

\section{References}

Giorgi, A., Pianesi, F. 2004. Complementizer deletion in Italian. In: Rizzi, L. (Ed.), The Structure of CP and IP. Oxford University Press, Oxford, 190-210.

Wandruszka, U. 1991. Frase subordinate al congiuntivo. In Renzi, L. \& G. Salvi (Eds.), Grande grammatica italiana di consultazione Vol. II. Il Mulino, Bologna, 415-481.

Josep Quer (ICREA)

Universitat Pompeu Fabra

Department Departament de Traducció i Ciències del Llenguatge

Roc Boronat, 138

08018 Barcelona

Spain

Telephone: +34 935421136

Fax: + 34935421617

E-mail: josep.quer@upf.edu 